\title{
Economic Impacts of Porcine Reproductive and Respiratory Syndrome (PRRS) Outbreak in Vietnam Pig Production
}

\author{
H. Zhang ${ }^{*}$ and H. Kono ${ }^{1}$ \\ Department of Animal and Food Hygiene \\ Graduate School of Obihiro University of Agriculture and Veterinary Medicine \\ Hokkaido, Japan
}

\begin{abstract}
Vietnam is a major pork producing country in Asia, but the pig farmers' livelihood was threatened by the pig disease; Porcine Reproductive and Respiratory Syndrome (PRRS). Data obtained from Food and Agriculture Organization of the United Nations Statistics Division (FAOSTAT), World Organization for Animal Health (OIE) and Information Center of Ministry of Agriculture and Rural Development (MARD) in Vietnam were rearranged and analyzed to study the economic impacts of PRRS outbreak in Vietnam. The results revealed that PRRS was introduced to Vietnam through international dissemination from China. This disease caused a sharp decline of pork price in the market and decreased the productivity and profitability of pig farming.
\end{abstract}

Keywords: Pig farming, pork price, Porcine Reproductive and Respiratory Syndrome

\section{INTRODUCTION}

Along with the economic growth, meat production has also been increasing in Asia (Fig. 1). A large part of meat production is devoted to pig production. Pigs are important for farmers as a major source of family income or as a 'savings bank' in Asia (Steinfeld, 1998). Vietnam is a major pork producing country in Asia, producing 2.9 million tons in 2009. (Fig. 2). Pork is the most important agricultural product in Vietnam, contributing $58 \%$ to the total agricultural GDP and $80 \%$ of the total meat production. Pig farming is an important income generating activity among agricultural population in rural areas in Vietnam. Up to $80 \%$ of pig farms are small-scale, typically comprised of one or two sows and less than 10 fattening piglets. Pig selling is the major income source of these farms (Lemke et al., 2008). Increasing the income from farming could be considered as a contribution to poverty reduction in this country. Figure 3 presents the similarity between the pig density and poverty population density in Vietnam and there is a close relationship between the poverty level the pork production industry. On the other hand, severe animal diseases tend to damage the pig production sector of this country.

Department of Hygiene Economics, Obihiro University of Agriculture and Veterinary Medicine, Hokkaido, Japan.

Author for correspondence: zhanghaifenga10@yahoo.com 


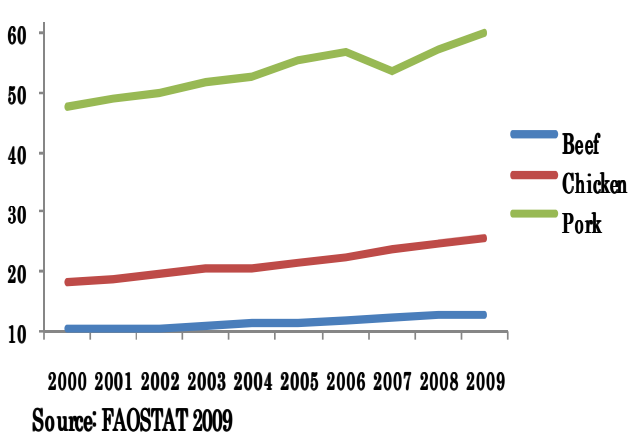

Fig.1. Meat production in Asia (In million tonnes)

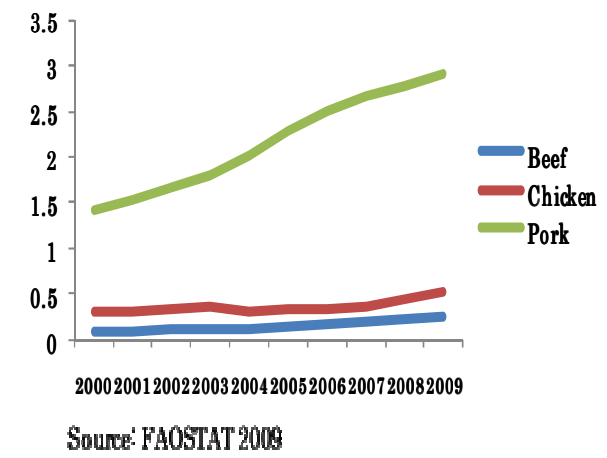

Fig. 2. Meat production in Vietnam (In million tonnes)

Porcine Reproductive and Respiratory Syndrome (PRRS) is one of the major endemic outbreaks in Vietnam in recent years. It brought not only damage to the pig farming, but also a huge socioeconomic damage to Vietnam. The objectives of this study are, to clarify the characteristics of PRRS disease, to identify the expansion of PRRS outbreaks and to estimate the economic impacts of PRRS on pig farming in Vietnam.
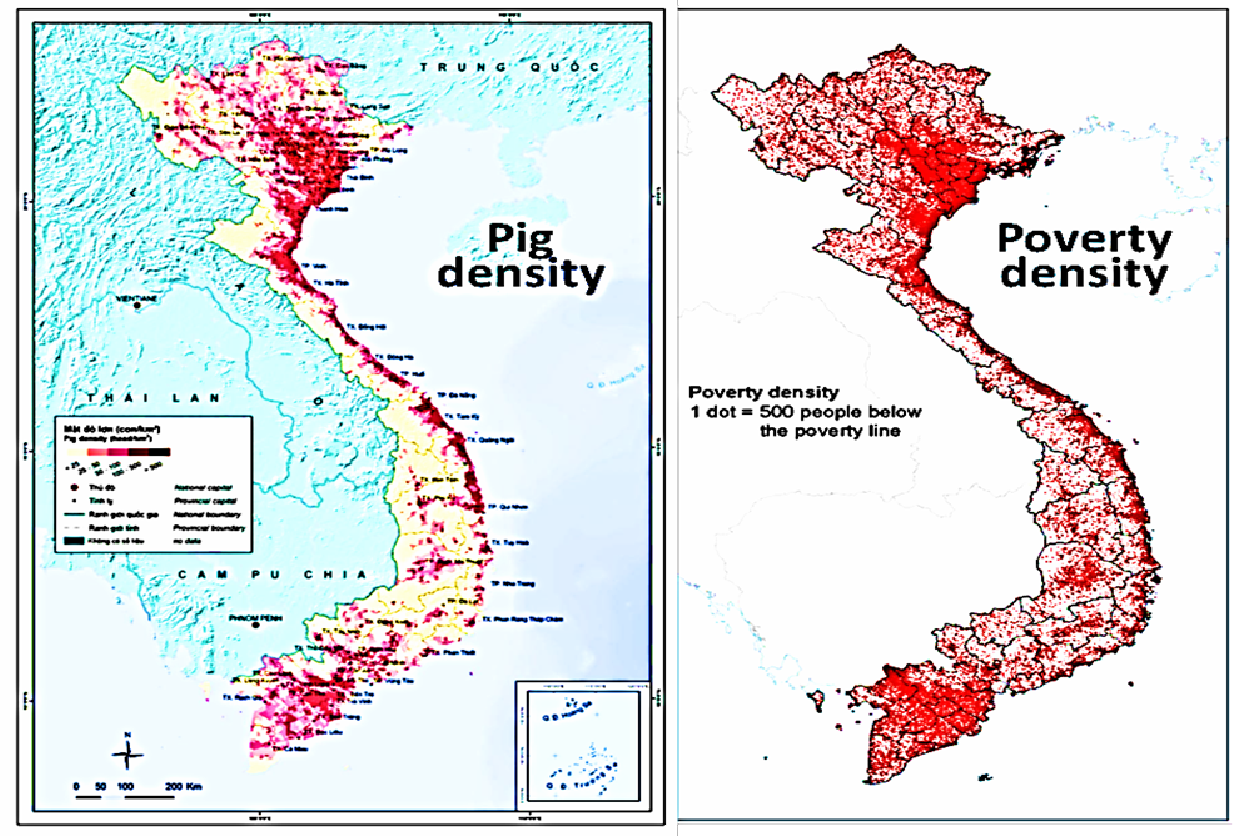

Fig. 3. Pig density and poverty density in Vietnam

Source: Information Center of Ministry of Agriculture and Rural Development (MARD) 


\section{MATERIALS AND METHODS}

A complete literature survey was carried to study pathogenicity and epidemic characteristics of PRRS virus to understand which characteristics damage the productivity and profitability of pig farming. Statistical data obtained from Food and Agriculture Organization of the United Nations Statistics Division (FAOSTAT), World Organization for Animal Health (OIE) was used to analyze the regional disease expansion pattern and pork market movement in Vietnam. Studies done at the Information Center of Ministry of Agriculture and Rural Development (MARD) were also used to understand the situation of pig farming in Vietnam. A field research was also conducted in August 2011 in Hue province of Vietnam to collect detail information of PRRS outbreaks in 2008.

\section{RESULTS AND DISCUSSION}
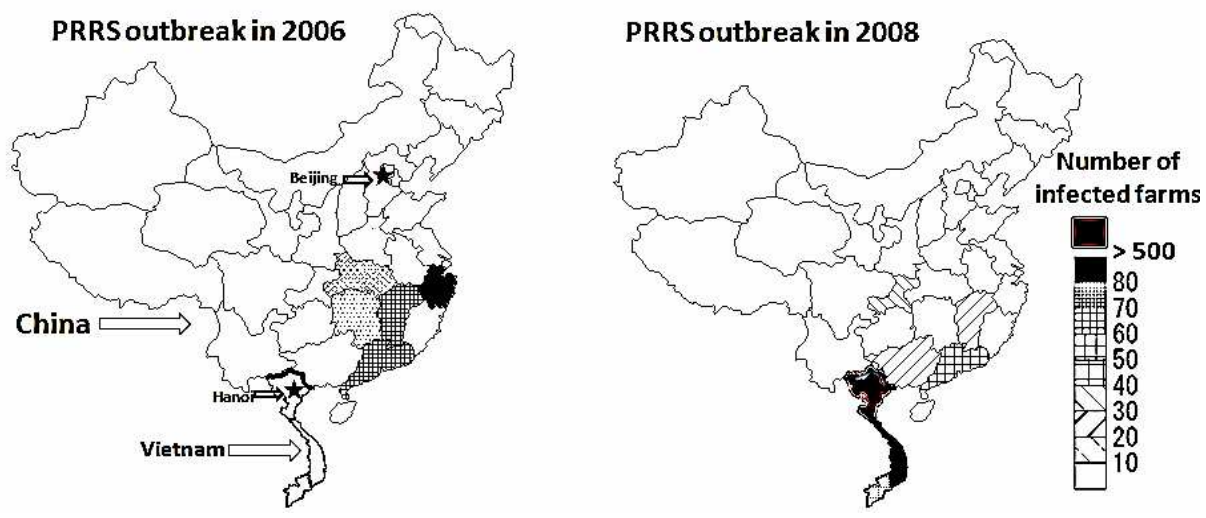

Fig. 4. PRRS outbreak movement from 2006-2008

Source: OIE

PRRS is a highly contagious viral disease of swine, and almost all countries around the world have been hit by this disease. The disease was first recognized in 1987 in the United Stated of America (Keffaber, 1989). The cost for controlling this disease in the USA was estimated to be $\$ 761.80$ million (Leaflet, 2005). In Asia, the first case of PRRS outbreak was reported from China in 1995, and in 2006, China was hit by an atypical highly virulent strain of PRRS virus. This atypical strain is called Highly Pathogenic Porcine Reproductive and Respiratory Syndrome (HP-PRRS) and resulted in huge economic losses to the Chinese pig industry (Tian et al., 2007). According to OIE data, 445 PRRS outbreaks were reported in China in 2006 that affected over two million pigs, of which 400,000 died, which was then spread to Vietnam (Fig. 4). Between March and August 2007, about 44,000 pigs were affected in Vietnam, of which over 4,000 died. In 2008, 1,077 outbreaks occurred and 300,906 pigs were infected (Fig. 4). The outbreaks were not much serious in 2009, but spread widely again in 2010 (Fig. 5). From the disease dissemination map, it could be considered that PRRS was spread from the south part of China to Vietnam (Fig. 4). The virus isolated from China and Vietnam showed $99 \%$ identity at the genomic level (Feng et al., 2008). 


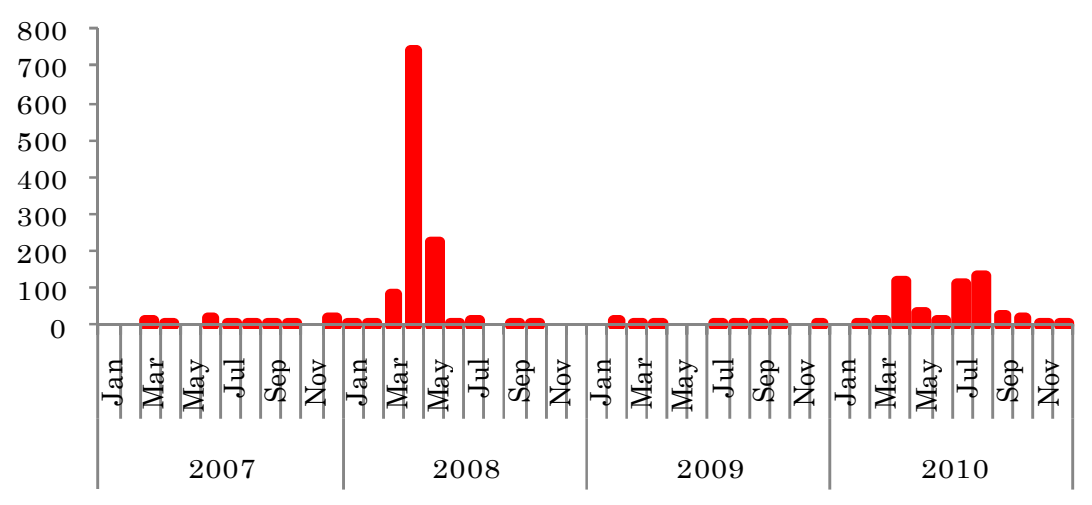

Fig. 5. PRRS outbreak numbers in Vietnam from 2007 to 2010

Source: OIE

The direct economic impact from PRRS on pig farms was the death of infected animals. Compared to PRRS-negative pigs, the PRRS-positive pigs had an increased death rate ranging from $2 \%$ to $12 \%$ in nursery piglet herds, and from $4 \%$ to $10 \%$ in finishing piglet herds (Fig. 6). However, the new variant of PRRS virus has much higher mortality rate than normal or typical PRRS (Fig. 7).

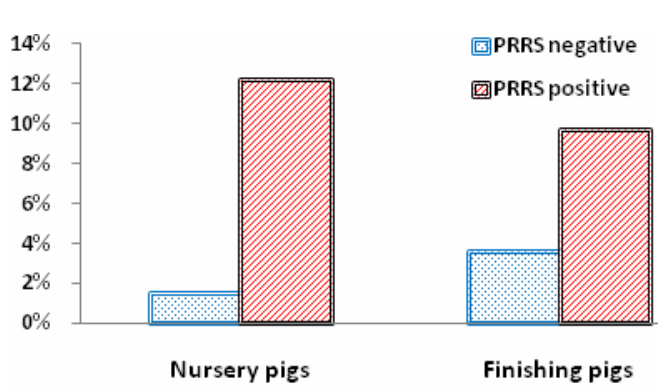

Source: Leaflet, 2005

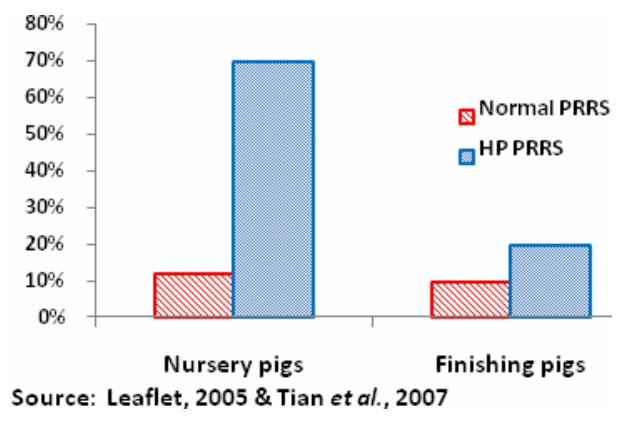

Fig. 7. Mortality rate of HP-PRRS infected Pigs

\section{Impacts of PRRS on pork market}

The market price of pork decreased by $29 \%$ in 2008 (Fig. 8). Compared to other meat products in the domestic market, although in the same year, the beef market was also damaged by Foot and Mouth Disease (FMD) and the chicken market was damaged by Avian influenza. Although, the market prices of beef and chicken were showing recovery in 2009, the price of pork was still remained in 2009, around 30\% below the price in January 2008. The PRRS had a much impact on the meat market than any other animal disease. 


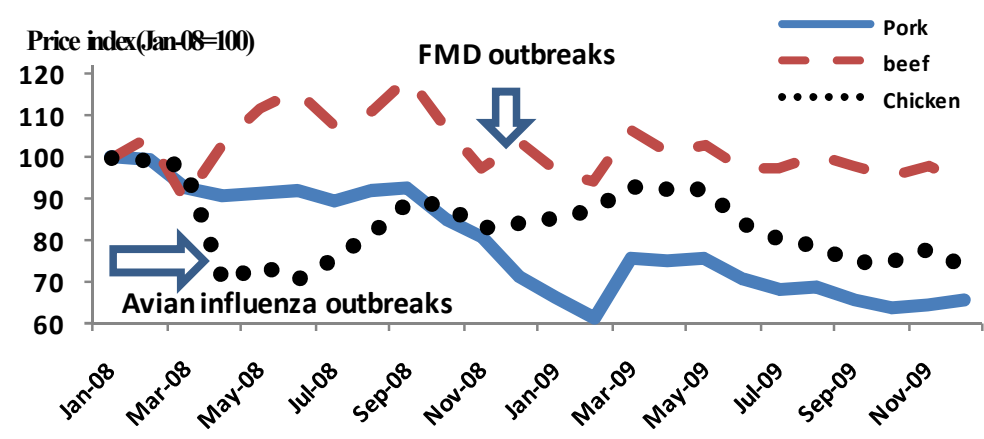

Fig. 8. Hanoi meat price index from 2008 to 2009

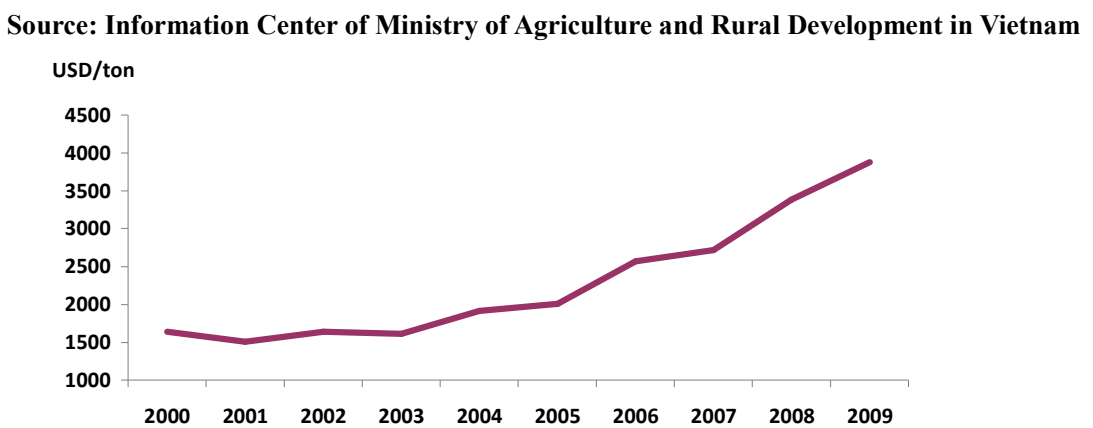

Fig. 9. Pork price in South East Asia

Source: FAOSTAT

Compared to the international market, along with the continuous income growth in SouthEast Asia, the price of pork also has been increasing constantly. Vietnam is also a fast economic developing country, and it is the only South East Asian country listed in the Next Eleven developing economics. The pork price was considered to have a similar growth rate with that of other South-East Asian countries as presented in Figure 9, but the price had been decreased by $30 \%$ during 2008, having a lower price in 2009. Except for Vietnam, the average pork price in South East Asian countries (Cambodia, Indonesia, Lao People's Democratic Republic, Malaysia, Philippines, Singapore, and Thailand) maintained a constant increase in recent years (Fig. 9). After the peak of the PRRS outbreaks in Vietnam, the pork price had been decreasing sharply, especially in the North part of Vietnam around capital city Hanoi where the major PRRS infection area was (Figs. $10 \& 11$ ). 


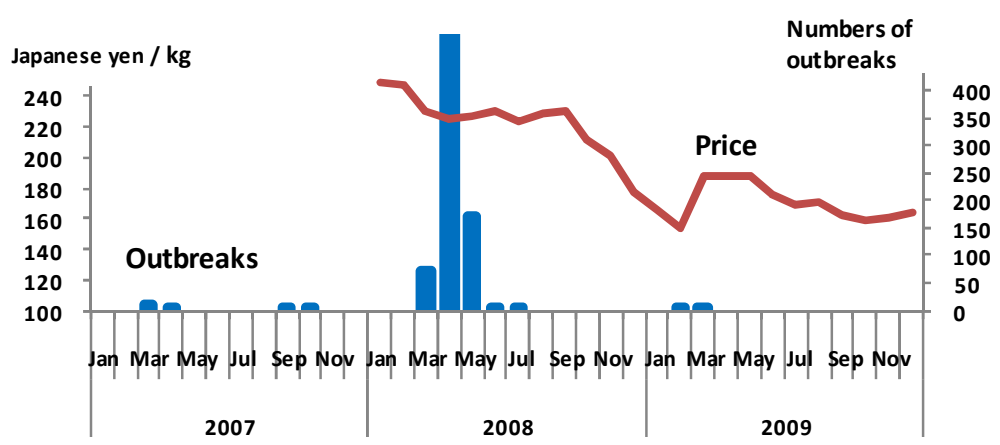

Fig. 10. Pork price in Hanoi and PRRS outbreaks in North part of Vietnam

Source: OIE \& Information Center of Ministry of Agriculture and Rural Development in Vietnam

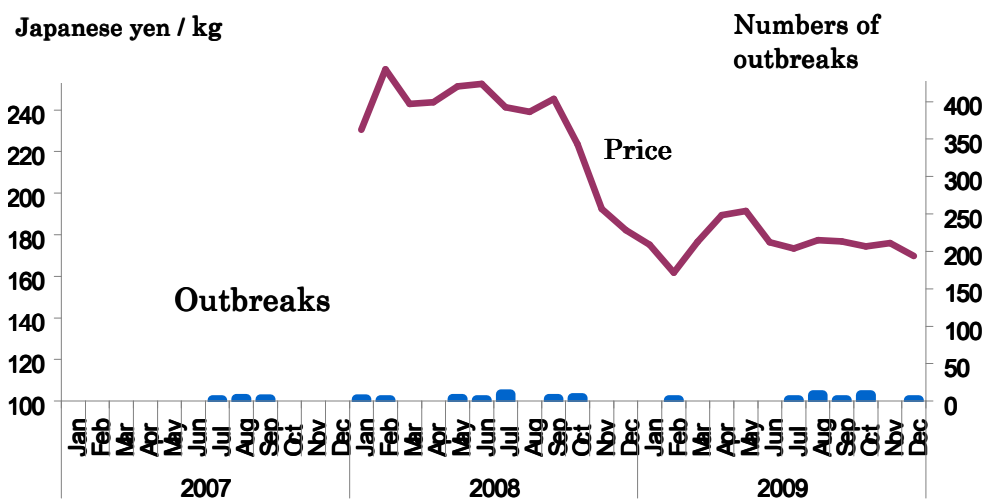

Fig. 11. Pork price in Ho-Chi-Min city and PRRS outbreaks in Southern part of Vietnam

Source: OIE \& Information Center of Ministry of Agriculture and Rural Development in Vietnam

Although the outbreaks mainly occurred in the Northern part of Vietnam, the impact of PRRS has affected the whole country. PRRS mainly occurred in the Northern part, but the pork price in the Ho-Chi-Min city (HCMC) of Southern part of the country was fluctuated similar to that with that of Hanoi of the Northern Vietnam (Figs. $10 \& 11$ ). The PRRS reduced the pork prices all around the whole country market.

According to an agricultural economic expert in Hue University in Vietnam, the consumers were threatened by the widespread PRRS and the demand of pork was decreasing. However, on the other hand, the pork production was increasing (Fig. 2) to keep the demand from the consumers, but the producers had to reduce the price. The PRRS damaged not only the pork market, but also the pig farms. 


\section{Economic impacts of PRRS on pig farmers}

A field research was carried out in Hue Province, Vietnam in August 2011 at two pig farms. The scale of the farms and the PRRS outbreak information are given in Table 1.

Table 1. PPRS outbreak information of two farms of different scales

\begin{tabular}{lllll}
\hline & Farm A & & Farm B \\
\hline Farm size & Sows & 2 & Sows & 20 \\
& Finishing hogs & 10 & Finishing hogs & 80 \\
Infected animals & Sows & 2 & Sows & 16 \\
& Finishing hogs & 5 & Finishing hogs & 66 \\
\multirow{2}{*}{ Number of death } & Sows & 0 & Sows & 0 \\
& Finishing hogs & 5 & Finishing hogs & 66 \\
\hline
\end{tabular}

Farm A is a small-scale one with 2 sows and 10 finishing hogs, and Farm B is a middle-sized farm with 20 sows and 80 finishing hogs. Both farms were damaged by PRRS seriously in 2008. Around $50 \%$ to $80 \%$ of their finishing hogs were infected and died. As selling finishing hogs was the main income source of the farmers, the large number of death brought huge economic impacts on their livelihood.

Further, the pig farms did not cull the infected sows, as the sows are the most important production capital for pig farming. Most farms, especially small-scale farms, produce piglets from their own sows (Lemke et al., 2008). If they culled infected sows, they had to purchase high price piglets from the market, so that their production cost for pig farming will become extremely high. Although they could get a subsidy from the government if they culled infected animals, the subsidy was small, only $50 \%$ of the market price of pigs, which might be not enough to cover the production cost.

Under such circumstances of pig farming in developing countries, the economic impacts would be enormous if they culled infected sows. Therefore, FAO recommended the PRRS infection area in South East Asia to avoid culling all infected animals as the subsidy was not enough (FAO, 2010). It could be conceived that the veterinary officers also gave similar advice to avoid culling infected sows because of insufficiency of subsidy.

On the other hand, since the pig farmers did not cull the infected sows, the infection might recur in the future, so that extra disease prevention methods are required. According to the FAO recommendation, the most effective PRRS prevention strategy is vaccination (FAO, 2007). Nevertheless, except of the big farms, almost no vaccination was conducted among the small-scale farms in Hue. Since the infected animals were not culled, subsidy given was not enough and sufficient disease control methods were not carried out, the PRRS recurred in 2010, which again damaged the pig industry in Vietnam.

\section{CONCLUSIONS}

The pig farms in Vietnam were damaged by PRRS outbreak, both by increase of the production cost and decrease of the pork price. Since pig farming was the major income source for most farmers in Vietnam, PRRS damaged their livelihood seriously. An efficient eradication program is necessary to prevent spread of the disease internationally. Since most 
of the pig farms in Vietnam were small-scale and did not have the ability to conduct the eradication, more governmental support is needed.

Furthermore, the subsidy for culling infected animals was not sufficient. Better subsidy scheme was necessary in order to support the livelihood of the farmers and prevent disease dissemination and also as an incentive for encouraging the farmers to cull and report infected animals.

\section{REFERENCES}

FAO Emergency Prevention Systems. (2007). Focus On: Porcine reproductive and respiratory syndrome (PRRS) regional awareness [on line]. [Accessed on 09.09.2011]. Available at http://www.fao.org/docs/eims/upload/235243/ai340e00.pdf.

FAO Emergency Prevention Systems. (2010). Focus On: Porcine reproductive and respiratory syndrome (PRRS) virulence jumps and persistent circulation in Southeast Asia [on line]. [Accessed on 09.09.2011]. Available at http://www.fao.org/docrep/013/al849e/al849e00.pdf.

Feng, Y., Zhao, T., Nguyen, T., Inui, K., Ma,Y., Nguyen, T.H., Nguyen,V.C., Liu, D., Bui, Q.A., To, L.T., Wang, C., Tian, K. and Gao, G.F. (2008). Porcine respiratory and reproductive syndrome virus variants, Vietnam and China, 2007. Emerging Infectious Diseases, 14, (11).

Leaflet, A.S. (2005). The impact of PRRS on the Pig Cost of Production. Iowa State University Animal Industry Report 2005.

Lemke,U., Mergenthaler, M., Rössler, R., Huyen, L.T.T., Herold, P., Kaufmann, B. and Zárate, A.V. (2008). Pig production in Vietnam - a review. CAB Reviews: Perspectives in Agriculture, Veterinary Science, Nutrition and Natural Resources, 3, (023).

Keffaber, K.K. (1989). Reproductive failure of unknown etiology. Am. Assoc. Swine Pract. Newsl. 1, 1-10.

Steinfeld, H. (1998). Livestock Production in the Asia and Pacific Region - Current Status, Issues and Trends. In: B,S, Hursey, (Ed.). World Animal Review, 90, 1.

Tian, K., Yu, X., Zhao, T., Feng, Y., Cao, Z., Wang, C., Hu, Y., Chen, X., Hu, D., Tian, X., Liu, D., Zhang, S., Deng, X., Ding, Y., Yang, L., Zhang, Y., Xiao, H., Qiao, M., Wang, B., Hou, L., Wang, X., Yang, X., Kang, L., Sun, M., Jin, P., Wang, S., Kitamura, Y., Yan, J. and Gao, G.F. (2007). Emergence of fatal PRRSV variants: unparalleled outbreaks of atypical PRRS in China and molecular dissection of the unique hallmark. PLoS One. 13:2(6): e526. 